\title{
ADMINISTRAÇÃO PARTICIPATIVA COMO FILOSOFIA PARA O GERENCIAMENTO DE SISTEMAS DE INFORMAÇÃO*
}

\author{
PARTICIPATIVE MANGEMENT AS A PHILOSOPHY FOR THE \\ ADMINISTRATION OF INFORMATION SYSTEMS
}

\author{
Edmeire Cristina PEREIRA** \\ estela@cieg.ufpr.br \\ Raquel Rutina KOROBINSKI*** \\ rutina@coruja.humanas.ufpr.br \\ Liane dos ANJOS**** \\ alian@coruja.humanas.ufpr.br \\ Suely Ferreira da SILVA***** \\ cedoc@ta.pr.gov.br

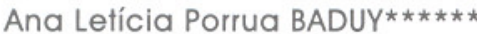 \\ leticiabaduy@latinmail.com
}

RESUMO

\begin{abstract}
Este artigo aborda, no atual contexto de transformações da sociedade do conhecimento, vários aspectos da administração participativa, concebida como uma filosofia para o gerenciamento dos sistemas de informação. Observa-se a necessidade de desenvolver informação, treinamento e comunicação, da parte das organizações, por meio desse novo paradigma de liderança. Tal proposta é situada na evolução das grandes tendências de pensamento e atualizada em função do desenvolvimento das redes e sistemas de informação. Em conclusão, sugerem-se alguns princípios elementares para redesenhar as atividades dos gestores da informação ou do conhecimento.
\end{abstract}

Palavras-chave: Administração Participativa; Empowerment; Autogestão; Trabalho em equipe; Liderança; Participação nos lucros; Gerenciamento de sistemas de informação.

(*) Trabalho originalmente apresentado em Seminário (29 e 30 out. 1999), na disciplina Administração de Sistemas de Informação, ministrada pela Profa. Dra. Cecilia Carmen Cunha Pontes, do Curso de Mestrado em Biblioteconomia e Ciência da Informação PUC-Campinas/UFPR.

(*) Professora Auxiliar III do Departamento de Ciência c Gestão da Informação (DECIGI), da Universidade Federal do Paraná (UFPR). Mestranda do Programa de Pós-Graduação cm Biblioteconomia c Ciência da Informação - Convênio CAPES/MINTER-PUC-Campinas/UFPR.

(...) Professora Auxiliar II do Departamento de Ciência e Gestão da Informação (DECIGI); da Universidade Federal do Paraná (UFPR). Mestranda do Programa de Pós-Graduação em Biblioteconomia e Ciência da Informação - Convênio CAPES/MINTER-PUC-Campinas/UFPR.

(…) Bibliotecária-chefe da Referência da Biblioteca de Ciências Humanas e Educação da UFPR. Mestranda do Programa de Pós-Graduação em Biblioteconomia e Ciência da Informação - Convênio CAPES-PUC-Campinas/UFPr.

(.....) Professora Auxiliar II do Departamento de Ciência e Gestão da Informação (DECIGI), da Universidade Federal do Paraná (UFPR). Mestranda do Programa de Pós-Graduação em Biblioteconomia e Ciência da Informação - Convênio CAPES/MINTER-PUC-Campinas/UFPR.

(…..) Bacharel em Biblioteconomia pela UFPR e Mestranda do Programa de Pós-Graduação em Biblioteconomia e Ciência da Informação - Convênio CAPES/MINTER-PUC-Campinas/UFPR. 


\title{
ABSTRACT
}

\begin{abstract}
Within the present context of transformations of the knowledge society, this paper contains many aspects of the participative administration, conceived as a philosophy for the information systems management. The need to develop information, training and communication is noted by the organizations through this new paradigm of leadership. Such a proposition is situated at the evolution of the great tendencies of thought and updated as a result of the development of networks and information systems. Some elementary principles are suggested to redraw the activities of the information or knowledge managers.
\end{abstract}

Kev-words: Participative management; Empowerment; Self-management; Team work; Leadership; Profit Participation; Information Systems Management.

\section{INTRODUÇÄO}

\begin{abstract}
"É preciso que o melhor governo seja aquele que possua uma constituição tal que todo o cidadão possa ser virtuoso e viver feliz".
\end{abstract}

\section{(ARISTÓTELES)}

Estamos diante de um novo fenômeno chamado de Terceira Revolução Industrial, alicerçada na microeletrônica e muito diferente da Primeira Revolução Industrial, surgida na Inglaterra, na segunda metade do século XVIII ao XIX e da Segunda Revolução Industrial, que teve seu início no final do século XIX e que se estendeu até a segunda metade do século XX. (AZEVEDO, 1996).

Na visão de PASSOS (1999), essa Terceira Revolução Industrial tem como características:

a) $\mathrm{O}$ desenvolvimento de um conjunto de inovações tecnológicas de largo espectro de utilização e mutuamente estimuladoras entre si, nas áreas de novos materiais, biotecnologia e, sobretudo e principalmente, na microeletrônica;

b) formas de gestão inovadoras vêm sendo implementadas de modo a superar a antiga organização por postos de trabalho fixos com tarefas ultra-especializadas, resultantes das análises de tempos de movimentos "taylorizados";

c) uma revolução nos processos produtivos designada como automação flexível vai superando a antiga automação rígida das cadeias fordistas de produção;

d) uma profunda modificação nos processos organizacionais, nas estratégias e na cultura das organizações empresariais.
Com certeza, por conta desse incrível progresso tecnológico, o mundo começou a ficar diferente, tornou-se globalizado e passou a exigir uma capacitação contínua dos atuais trabalhadores dentro das empresas, por causa das inovações nos processos, projetos e produtos.

Como conseqüência desse fenômeno mundial que é a globalização, o mundo está vivendo uma de suas piores crises nas esferas produtiva e financeira, ao ter de enfrentar novos paradigmas do mundo do trabalho e da produção. O grande desafio a enfrentar, hoje em dia, é "como pilotar na turbulência".

Talvez, uma solução seja a adoção da Administração Participativa para aumentar os ganhos em qualidade e produtividade, a exemplo das experiências bem-sucedidas do Japão, Suécia e Alemanha, cujo modelo concreto mais avançado é o do toyotismo.

CARVALHO (1995) corrobora dessa idéia, ao afirmar:

"O baixo clero gerencial começa a desaparecer à medida que os trabalhadores incorporam essas habilidades, através da capacitação, sendo capazes de ganhar autonomia e criar co-responsabilidades no processo técnico de trabalho. Isto é de fato a Gestão Participativa, significando uma alteração radical nas relações de poder, nas relações técnicas de trabalho, nos valores e na cultura das organizações ".

Neste artigo, a Administração Participativa será enfocada como uma filosofia imprescindível nos dias de hoje, para o gerenciamento dos sistemas de informação.

\section{ANTECEDENTES}

A Administração Participativa ou, propriamente, a idéia de participação não é algo novo. Remonta, 
historicamente, aos gregos antigos, quando estes analisavam as diferentes concepções de poder. Por exemplo: é no governo de Clístenes, no final do século VI a.C., que o regime ateniense se democratiza, com a redução do poder da nobreza territorial provocada por uma nova distribuição das famílias em diversas tribos. E é no século V A.C., na época de Péricles, um estratego, ou seja, um general superior, que se dá o apogeu da democracia. Inclusive, Aristóteles chegou a estabelecer uma tipologia das formas de governo que se tornou clássica:

\begin{tabular}{|l|l|l|}
\hline CLASSIFICAÇÃO DAS FORMAS DE GOVERNO \\
\hline \multirow{2}{*}{ Critério do número } & \multicolumn{2}{|c|}{ Critério do valor } \\
\cline { 2 - 3 } & Boas & Corrompidas \\
\hline Um & Monarquia & Tirania \\
\hline Poucos & Aristocracia & Oligarquia \\
\hline Muitos & Politéia & Democracia \\
\hline
\end{tabular}

Fonte: ARANHA \& MARTINS (1995, p. 196).

Apesar de Aristóteles ter classificado a democracia como uma forma corrompida de governo, não nos cabe aqui, neste artigo, imiscuirmos nessa seara filosófica. Fiquemos apenas com a noção de que o que parece novidade, na verdade, não o é.

O conteúdo ideológico desta moderna concepção de participação remonta às doutrinas sociais do século XIX, surgidas com a Revolução Industrial. Marx a definiu sendo a mais valia. Proudhon defendeu a propriedade coletiva gerada pelo trabalho coletivo e que, portanto, deveria ser distribuída aos trabalhadores, de forma que cada um recebesse o equivalente à riqueza que gerava.

Rousseau, Stuart Mill e Tocqueville são considerados os patronos da corrente democrática que possuía a participação nas empresas como uma extensão da democracia política da sociedade civil, incorporando valores democráticos no âmbito da empresa.

A participação nos lucros vem sendo implantada cada vez mais com relativo sucesso em várias empresas de diversos países e é vista por alguns autores como um dos alicerces para o desenvolvimento efetivo de uma filosofia de administração participativa nas empresas (FERREIRA, 1998). Porém, só veio a despertar o interesse das organizações, notadamente, após a Segunda Guerra Mundial, especificamente, em território japonês.

\section{CONCEITUAÇĀO}

Para os termos participação e administração participativa, fomos buscar em FERREIRA (1998) uma melhor compreensão:

"Participação consiste basicamente na criação de oportunidades paraque as pessoas influenciem decisões que as afetarão. Essa influência pode variar pouco ou muito. Participação é um caso especial de delegação, na qual o subordinado obtém maior controle, maior liberdade de escolha em relação às suas próprias responsabilidades."

"Administração participativa é uma filosofia que exige que o processo organizacional de tomada de decisões seja feito de forma que os recursos $e$ responsabilidades necessários sejam estendidos até o nível hierárquico mais apropriado. O propósito da administração participativa é assegurar que decisões efetivas sejam feitas pelas pessoas certas."

"A administração participativa é uma filosofia ou política de administração de pessoas que valoriza sua capacidade de tomar decisões e resolver problemas. A administração participativa aprimora a satisfação e a motivação no trabalho. A administração participativa contribui para o melhor desempenho e a competitividade das organizações."

"A participação é fruto de uma tendência inelutável que podemos deduzir dos processos de desalienação e que tende a se manifestar em toda ação coletiva. "

"São várias as definições dos autores para 'administração participação', ou até mesmo para 'participação'. Dado que não se trata de um tema novo mas com profundas raízes históricas, pode ser interpretado de maneira diferente, por distintas categorias de pessoas, dos mais variados países e em diversas épocas. Além disso, o tema está intrinsecamente relacionado a outros tópicos, como empowerment, autogestão, trabalho em equipe, liderança, participação nos lucros."

A participação não tem origem com o nascimento do ser humano. Ela é uma habilidade que pode ser adquirida no relacionamento do indivíduo nas várias esferas da sociedade, ou seja, no lar, na escola, na comunidade e na empresa. Assim, é possível aprendê-la, modificá-la e aperfeiçoá-la.

Segundo DÍAZ BORDENAVE (1987), há vários níveis e maneiras de participar e de atribuir também uma qualidade ao ato de participar. Dependendo das circunstâncias, a ação participativa se realiza com maior ou menor êxito. Assim, tem-se que: 
a) a participação é mais intensa quando se vincula ao interesse do indivíduo e do grupo, desde que seus integrantes se conheçam e haja canais confiáveis de comunicação;

b) as diferenças individuais constituem-se em uma intensa força para o dinamismo e funcionamento do grupo, levando a um grau maior de produtividade, de satisfação e de responsabilidade de seus componentes;

c) a participação torna-se mais efetiva quando o processo de realização permite ao indivíduo e ao grupo sentir os efeitos concretos e imediatos de seu desempenho;

d) a discussão de idéias, o respeito da opinião alheia, a aceitação de experiências positivas ou negativas, enfim, o saber dialogar pode levar a um acordo satisfatório às apreciações do grupo, proporcionando maior participação de seus integrantes;

e) não é suficiente a vontade e a espontaneidade por parte dos que se envolvem com o ato de participar. A participação atinge a eficácia quando é realizada de modo a estabelecer a paridade entre as pessoas, portanto, sem "hierarquismo";

f) o grau de participação dos indivíduos é inversamente proporcional ao tamanho do grupo. Isto é, o grande grupo tem maiores recursos, mas o grau de participação das pessoas, em grupos menores, é maior.

As maneiras de participar também variam em conformidade com as diversas formações sociais, isto é, a harmonia da estrutura sócio-econômica, com o regime jurídico-institucional e fatos culturais.

Assim sendo, encontram-se no Capítulo II da Constituição da República Federativa do Brasil (promulgada em outubro de 1988) - Dos Direitos Sociais "Art. 7. São direitos dos trabalhadores urbanos e rurais, além de outros que visem à melhoria de sua condição social: a participação nos lucros, ou resultados, desvinculada da remuneração e, excepcionalmente, participação na gestão da empresa, conforme definido em lei". Lei esta, ainda, não regulamentada.

\section{CONCEPÇÕES DE PARTICIPAÇÃO}

Há diferentes concepções de participação encontradas em diversos tipos de organização. Algumas dessas concepções são: Visão Socialista; Teoria Democrática; Relações e Desenvolvimento Humanos e Produtividade e Eficiência (MENDONCA apud FERREIRA, 1998):

a) Visão Socialista: baseada nas idéias de Fourier, Marx e Proudhon aspira à construção de uma sociedade participacionista e autogestionária em todas as esferas nas quais o homem se desenvolve.

b) Teoria Democrática: tem Rousseau, Stuart Mill e Tocqueville como patronos, postulando a incorporação de valores democráticos no âmbito das empresas.

c) Relações e Desenvolvimento Humanos: procura desenvolver mecanismos de participação através da ênfase em arranjos organizacionais voltados a garantir o desenvolvimento dos indivíduos e dos grupos, acreditando sempre que tudo pode ser resolvido através de boas relações e ignorando conflitos de poder e de classes.

d) Produtividade e Eficiência: esta concepção postula uma maior participação na tarefa, na qual o foco é deslocado da participação para o conteúdo do trabalho, através de diferentes estratégias, a exemplo do enriquecimento das funções e do cargo.

Todas estas concepções identificam o mesmo objetivo: responsabilidades sociais da empresa, equilíbrio dos interesses dos vários envolvidos, cultura democrática, redução da alienação, utilização do potencial das pessoas, diminuição de conflitos, satisfação e maior competitividade.

\section{FORMAS DE PARTICIPAÇÃO}

Tradicionalmente, divide-se a participação em direta e indireta: a primeira está dirigida a uma pessoa individualmente, e a segunda diz respeito à participação dos trabalhadores, coletivamente, conforme se pode observar no quadro, a seguir, construído a partir das idéias de FERREIRA (1998):

\subsection{Formas de Participação à Brasileira}

Já fora dito, anteriormente, neste trabalho, que estamos às voltas com o mais sério problema estrutural da virada do século, ou seja, o desemprego estrutural. Este fantasma aparece não só para os países pobres, como também para os ricos. SILVA (1996), escrevendo na Folha de São Paulo sobre o livro de Jeremy Rifkin O Fim dos empregos, recupera este pensamento do 
autor: "Na Primeira [revolução], quem perdeu emprego na agricultura foi para a indústria. Na Segunda, quem saiu da indústria foi para os serviços. Agora, quando o setor de serviços está sendo "desmontado" pela tecnologia, não há opção" Ele mostra que, nos anos 60, os empregados em indústrias eram 33\% da força de trabalho. Agora são $12 \%$ e em 2020 serão $2 \%$.

Enfim, a atual revolução tecnológica não precisa mais de trabalho em massa. Teremos de conviver com menos empregos ou com menos tempo nos empregos. Recentemente, a Revista Veja editou matéria de capa, intitulada: Mais lazer e menos trabalho? Esquece, onde argumenta que a tecnologia e os sindicatos prometiam reduzir as horas de trabalho. Deu o contrário, o Brasil, assim como outros países, está na linha de frente dos países que mais trabalham, em média de horas (1927) por ano, contra a Cingapura ( 1 o lugar), que trabalha em média por ano 2.307 horas, em comparação com a Nova Zelândia (última da lista), com 1838 horas (VEIGA, 2000).

Diante desse problema, o Brasil tem adotado por filosofia a de que a autogestão pode representar uma salvaguarda efetiva dos empregos. Chegou, inclusive, a criar, em 1992, a ANTEAG - Associação Nacional dos Trabalhadores em Empresas de Autogestão e Participação Acionária. Essa associação abarca 33 empresas autogestionárias, responsáveis por quase 6.000 empregos diretos. E segundo a ANTEAG, as empresas afiliadas se classificam assim:

a) Empresas de autogestão, onde os trabalhadores têm mais de 51\% das ações;

\section{CARACTERÍSTICAS DA PARTICIPAÇÃO DIRETA E DA}

\section{PARTICIPAÇÃO INDIRETA}

\section{PARTICIPAÇÃO DIRETA}

Há grande aceitação nos Estados Unidos, agindo na integração informal, principalmente, como estilo gerencial.

- Integração do indivíduo à organização, possibilitando perceber as origens dos conflitos individuais.

- Somente em 1950 é que ganhou projeção enquanto abordagem gerencial da questão da motivação capaz de superar o conflito entre o funcionário e a organização.

- Aparecem o enriquecimento e a ampliação das tarefas, o trabalho em equipe, a rotação de cargo, nas propostas de várias técnicas para implementação de uma cultura participativa. Todas elas com pontos comuns e nos quais percebe-se que a organização deve investir necessariamente em informação, treinamento e comunicação. Através desses três elementos cria-se um ambiente participativo, no qual os próprios funcionários encontrarão alternativas a problemas, incluindo sua participação nas decisões, nos resultados e nas modificações na estrutura organizacional.

\section{PARTICIPAÇÃO INDIRETA}

Há quatro formas possíveis de participação indireta, para MOTTA apud FERREIRA, sendo que as mesmas, influenciam diferentemente o processo decisório:

1a) Comitês de empresa - sua função é consultiva ou cooperativa, com pouco poder de decisão, ficando mais relacionado à área de administração pessoal;

2a) Negociações coletivas - estabelecem condições gerais de emprego e trabalho, entre negociações com dirigentes e sindicalistas;

3) Co-gestão - realizada através da representação dos funcionários na direção efetiva da empresa, em órgãos e proporções variadas. Tem objetivo de estabelecer a cooperação e harmonia entre sindicatos e empresas. Há que se destacar o ano de 1918, na Alemanha, quando foi instituída a organização obrigatória de comissões de trabalhadores e empregados para toda a economia. Atualmente, existem oito variantes de co-gestão implantadas na Alemanha e cerca de vinte milhões de empregados trabalham usufruindo de participação.

$4^{a}$ ) Autogestão - realizada a través do exercício coletivo do poder, pela autonomia dos grupos de membros da empresa para decidir sobre os destinos, processos e resultados dos trabalhos. A primeira experiência nesse sentido foi na França, na época da Comuna de Paris (1872). 
b) Empresas de co-gestão participativa, onde os trabalhadores têm entre $20 \%$ e $51 \%$ das ações;

c) Cooperativas de autogestão, têm no máximo $5 \%$ de empregados contratados, sendo os restantes cooperados formais que controlam a cooperativa (FERREIRA,1998).

No final dos anos 80, SEMLER (1988) também procurou usar da Administração Participativa para recuperar a empresa de seus pais. Narra em seu best-seller Virando a própria mesa, as experiências que realizou e, em especial, a criação dos dez mandamentos para a empresa atrair e manter pessoas:

I) Salário e benefícios adequados.

II) Respeito pelo indivíduo.

III) Produto que seja capaz de gerar orgulho.

IV) Sensação de envolvimento e espírito de equipe.

V) Espaço para opinar.

VI) Redução da distância entre a cúpula e a base.

VII) Preocupação com treinamento e aperfeiçoamento.

VIII) Seriedade incontestável da empresa.

IX) Relativa segurança no emprego.

X) Profissionalismo, com ausência de favorecidos e protegidos.

\section{PARTICIPAÇÃO PRECISA DE PARCEIROS}

Toda empresa é um sistema que recebe insumos do seu ambiente externo, e após processá-los e transformá-los, os devolve para o mercado. Essa relação, na visão de TAVARES (1992), inclui vários participantes:

a) Empregados - são as pessoas que contribuem com seu tempo e esforço para a organização, fornecendo habilidades e conhecimentos em troca de salários e de outros incentivos que a organização proporciona;

b) Investidores - são as pessoas ou instituições que contribuem com os investimentos financeiros que proporcionam a estrutura de capital e os meios para o financiamento das operações da empresa e esperam retorno para o seu investimento;

c) Fornecedores - são as pessoas ou instituições que contribuem com recursos para a produção, sejam materiais, matérias-primas, tecnologia, serviços (como consultorias, assessoria, propaganda e manutenção), energia elétrica, componentes e outros, em troca de remuneração de seus produtos/serviços e condições de continuidade de suas operações;

d) Distribuidores - são as pessoas ou instituições que adquirem os produtos ou serviços produzidos pela organização e os distribuem para o mercado de clientes ou consumidores em troca de remuneração de suas atividades e continuidade de suas operações;

e) Consumidores - são as pessoas ou instituições que adquirem os produtos ou serviços produzidos pela organização para utilizá-los e consumi-los na expectativa de satisfação de suas necessidades.

\section{RESISTÊNCIAS À IMPLANTAÇÃO DA ADMINIS- TRAÇÃO PARTICIPATIVA}

MENDONÇA (1992) alerta para o fato de que em pelo menos três níveis, na sociedade, a questão da participação se manifesta:

a) no nível macro, isto é, no âmbito da sociedade civil;

b) na esfera da relação entre cidadão, contribuinte e usuários; e no

c) espaço das empresas, cujo enfoque volta-se para a participação dos empregados no processo de tomada de decisão.

Não há um modelo rígido e inflexível de Administração Participativa, à rigidez prescritiva da denominada administração científica

Todos os níveis apresentam de alguma forma resistências e dificuldades para a viabilização da Administração Participativa. Nas organizações empresariais, as resistências ao modelo são classificadas em: resistências conceituais e resistências operacionais.

Quanto às resistências conceituais, dizem respeito à concepção que se possui sobre as organizações, sobre os traços da cultura brasileira em relação ao ethos do trabalho e principalmente ideológicas, as quais relacionam-se à ameaça de poder e à perda de legitimidade de autoridade e de status.

As resistências operacionais relacionam-se ao modelo de crescimento econômico adotado pelo país; à relação de autoridade instituída entre gerentes e subordinados; aos modelos empresariais com pouca visão estratégica e finalmente à resistência chamada de psicossocial. Esta trata da instabilidade, de destruição, 
reação predatória das relações entre as empresas e empregados no país.

Em decorrência das resistências citadas anteriormente, pode-se afirmar sobre a existência de pelo menos dois tipos de conflitos numa empresa: os de origem política e os de interesse de classes e de trabalho. Ambos detêm em suas bases as relações de poder.

Os conflitos políticos são gerados por interesses particulares e individuais. Através de um líder, arrebanha-se um maior número de pessoas possível que permita instaurar um quadro de luta por interesse. A dificuldade de trabalhar esse tipo de conflito é que não se enxerga claramente qual é o objetivo dos diferentes grupos, seus interesses reais e suas bases ideológicas.

Os interesses de classe e de trabalho são mais perceptivos e possuem características mais concretas. Se concordam com a missão e a ideologia da empresa, os empregados iniciam suas lutas por melhores condições de trabalho, participação nos resultados, salários, jornadas de trabalho, entre outros. São os chamados conflitos distributivos. Esse tipo de conflito, por ser comum à maioria dos trabalhadores, é facilmente agregado e trabalhado pela cúpula empresarial.

A participação tem sido uma aliada, uma arma gerencial encontrada pelos dirigentes para resolver conflitos e agradar aos divergentes grupos de interesses dentro das organizações.

A participação passou a ser encarada como estratégia gerencial que tem tornado possível uma colaboração mútua tanto no nível operacional, quanto no gerencial. Ela vem possibilitando, ainda, um nível de satisfação e responsabilidade dos empregados nos diferentes níveis da organização.

\section{TENDÊNCIAS}

As organizações do próximo milênio terão cada vez mais que mudar o alvo de suas atenções, passando de uma visão meramente tecnicista, para uma mais humanística, holística, talvez quântica, orientada por valores, comprometida com sua missão, focada nas pessoas e resultados, assumindo responsabilidades de Learning Organizations (CARVALHO, 1995).

Apresentamos algumas posturas que, acreditamos, podem se constituir em tendências ou "variantes" da Administração Participativa.

\subsection{Teoria Holística}

A palavra holismo, vem do grego holos, que significa todo. Parte do princípio de que o homem é um ser indivisível, que não pode ser entendido através de uma análise separada de suas diferentes partes.

Os anos 70 geraram uma série de movimentos filosóficos, espirituais e políticos que parecem caminhar na direção de restabelecer um equilíbrio dos aspectos da natureza humana. Percebe-se um direcionamento para uma visão sistêmica de vida.

Os organismos são sistemas auto-organizadores que exigem um alto grau de estabilidade. Essa estabilidade é profundamente dinâmica e caracterizada por flutuações contínuas, múltiplas e interdependentes. Para ser saudável, tal sistema precisa ser flexível, dispor de um grande número de opções para a interação com seu meio ambiente.

Seja qual for a natureza da flexibilidade, física, mental, social, tecnológica ou econômica, é essencial para a capacidade do sistema que se adapte às mudanças ambientais. Perda de flexibilidade significa perda de saúde.

É no contexto da globalização política e econômica que surge a busca de uma sabedoria sistêmica, que podemos interpretar como sendo a busca de uma visão holística. A visão holística pode ser considerada a forma de perceber a realidade e a abordagem sistêmica o primeiro nível de operacionalização desta visão, sendo ambas aplicáveis a todas as áreas do conhecimento.

$\mathrm{Na}$ área da administração, a empresa não é mais vista como um conjunto de departamentos, que executam atividades isoladas, mas como um corpo uno, um sistema aberto em contínua interação com o ambiente.

A visão holística está mais para uma forma de pensar, de perceber a realidade, do que para um modelo (a prática da visão holística seria o enfoque sistêmico). holística:

Algumas características da administração

a) Os dois lados do mesmo cérebro - privilegiando uma visão global, o holismo defende que ambos os hemisférios do cérebro devem ser interligados ou ter igual importância, conceito semelhante ao da "inteligência emocional";

b) A não matéria - a empresa holística agrega dois valores: a não matéria (aspectos intangíveis da organização) e o tempo (tempo real). O tempo real significa que não há um tempo para cada atividade, tudo devendo ser feito ao mesmo tempo. A prioridade é atribuída aos aspectos intangíveis e não à matéria ou ao tempo;

c) Fim da estrutura de cargos - a auto compreensão e a visão global favorecem a 
individualidade. As funções continuam existindo, embora desapareça a estrutura de cargos rígida e autoritária.

Mais importante do que tentar traduzir a visão holística em um só modelo, seria compreender o desdobramento deste modo de pensar nas modernas estratégias de gestão e nos desafios enfrentados pelos administradores.

\subsection{Teoria Quântica}

Teóricos da administração, consultores e afins vem aplicando a física quântica, os estudos das teorias da complexidade e do caos, as últimas descobertas sobre o funcionamento do cérebro, a ciência computacional e os avanços na biologia para tecer novas teses sobre como gerenciar as empresas. As aplicações das novas teorias nas áreas humanas só cistão começando.

Segundo a física e filósofa da ciência Danah ZOHAR (1998), formada pelo Massachusetts Institute of Technology (MIT), pela Universidade de Harvard, nos Estados Unidos, e pela Hebrew University, em Israel: "Todo esse conjunto de ciências do século XX traz novos paradigmas, muda os conceitos fundamentais a partir dos quais compreendemos o mundo. Com eles, podemos ver coisas que não percebíamos antes." Em seu mais recente livro, Rewiring the corporate brain, da editora Berret-Koehler, ela diz que são as conexões entre neurônios no cérebro que determinam a nossa capacidade mental. Nossas experiências determinam o tipo de conexões que faremos, o modo como vamos estruturar as relações entre os neurônios. (Até pouco tempo atrás, acreditava-se que esse processo se completava quando o indivíduo tinha por volta de18 anos. Hoje, os neurocientistas sabem que pessoas de mais de 90 anos ainda têm condições de mudar as conexões em seus cérebros.)

Diferenças de paradigma entre a Física Clássica (Newtoniana) e a Física Quântica:

a) Holismo - o modelo da física clássica, como o da filosofia grega, é atomista (o todo é formado pelas suas partes - a interação delas explica o conjunto). A organização quântica é holística (nenhum pedaço pode ser visto separadamente do todo sem que haja uma distorção ou perda);

b) Indeterminismo - na física clássica, cada efeito tem sua causa. Dada as leis corretas, tudo pode ser previsto. Nas teorias quântica e do caos, não há previsibilidade, não há controle possível. A organização quântica deve ser flexível. É a sua indeterminação que a torna capaz de evoluir em qualquer direção;

c) Auto-organização - o que vale na física clássica é o reducionismo e a análise (para qualquer realidade, constrói-se um modelo simples o suficiente para que se possa entender e amplo o bastante para dar conta da realidade). Um sistema quântico tem propriedades e potencial não apresentados pelas partes que o compõem (quando isolamos uma partícula, nós a reduzimos e possibilidades complexas viram uma só realidade). Uma empresa quântica deve ser auto-organizada e emergente. Deve valorizar a criatividade, deve deixar fluir a informação e a troca de idéias. As partes (indivíduos, equipes, setores) devem ser livres para se reorganizarem;

d) Ambos, não um ou outro - na física clássica, uma partícula está aqui ou lá, agora ou em outro tempo. Como no princípio de identidade aristotélico, algo é ou nãoé. Na física quântica, essa lógica não se aplica. As partículas têm comportamento de partículas e, ao mesmo tempo, agem como se fossem ondas (em 1906, o cientista J.J.Thomson recebeu o Nobel de Física ao demonstrar que os elétrons eram partículas - em 1937, o filho dele, G.Thomson, recebeu o mesmo prêmio ao demonstrar que os elétrons eram ondas. Ambos tinham razão). Uma empresa quântica deve aproveitar a diversidade. A antiga visão de uma verdade, um caminho, um modo de fazer as coisas deve dar lugar à pluralidade, deve acomodar as multiplicidades da sociedade, do mercado, dos indivíduos;

e) O mundo é incerto - por mais que se façam planos, sempre pode aparecer algo para atrapalhar ou ajudar, no meio do caminho. Hoje, já há base científica para se afirmar que o mundo é incerto. Segundo o princípio da incerteza de W. Heisenberg, é impossível determinar ao mesmo tempo a posição e a velocidade de uma partícula. A questão não é a falta de um aparelho preciso, é a impossibilidade real. De acordo com ZOHAR (1998), uma organização quântica seria menos parecida com uma orquestra e mais parecida com uma jam session;

f) Potencial não real - avaliações de desempenho fazem parte do mundo mensurável, que pode 
ser analisado, controlado, verificado. Tanto a teoria da complexidade quanto a teoria quântica falam de potencial, mais do que de realidade. Na física quântica, todas as asserções dizem respeito a probabilidades. Uma organização quântica seria brincalhona;

g) Universo participativo - para a ciência clássica, um experimento se divide entre o sujeito e o objeto, o observador e o fenômeno. Um dos paradigmas da física quântica é a impossibilidade de estudar um fenômeno por si, como se o observador não existisse. A observação modifica a realidade. Há tantas perspectivas do universo quantos observadores existem, disse Einstein. Uma empresa quântica seria ecológica, teria consciência da Terra como um sistema integral, com o homem inserido nela. Ela seria participativa nos ambientes social, cultural e natural;

h) O vácuo - cada objeto é um padrăo de organização de energia. "Em um período de sete anos, toda a matéria do nosso corpo muda, todas as moléculas de água, gordura e proteína mudam completamente. No entanto, continuamos sendo a mesma pessoa" (ZOHAR, 1998). Uma organização quântica seria centrada em sua visão e dirigida por seus valores. Os valores seriam como o vácuo quântico. A partir deles seriam organizados os padrões de energia que representam os produtos, as relações e os serviços (COHEN, 1998). A teoria quântica usa de metáforas para compreender situações complicadas e atuar de acordo com uma nova perspectiva. $\mathrm{O}$ líder quântico seria alguém sábio o suficiente para manter-se no limite, saber quando usar a teoria clássica e quando usar os novos paradigmas.

\subsection{Learning Organizations}

Há onze anos, Peter SENGE, o autor de A quinta disciplina lançou o conceito de learning organizations. O livro foi mais do que um best-seller de Administração - foi uma revolução. Criou uma linguagem que estava ao alcance de todos os tipos de empresa, proporcionou a visão de locais de trabalho acolhedores e empresas erguidas em torno da aprendizagem.

SENGE e seus colegas publicaram recentemente The dance of change: the challenges to sustaining momentum in learning organizations. O livro começa com duas lições. A primeira é que iniciar e manter mudanças é um empreendimento mais difícil do que sugeriu o tom de A quinta disciplina. A segunda é que a tarefa de fazer mudanças acontecerem exige que os empresários mudem a maneira como encaram as organizações. "Precisamos pensar menos como administradores e mais como biólogos", diz SENGE.

$\mathrm{Na}$ era das máquinas, também a empresa virou uma máquina de ganhar dinheiro. Ironicamente, a palavra companhia não poderia ter sido mais distorcida do que dessa forma. Suas raízes remontam há muito antes da era industrial. Ela tem a mesma raiz da palavra companheiro. No decorrer da revolução industrial, esse sentido se modificou e a companhia foi ficando mais e mais semelhante a uma máquina. Há pessoas que projetam essa máquina. Elas a montam e a colocam para funcionar. São os fundadores. Há pessoas que operam e controlam a máquina. São os administradores. O modelo de companhia-máquina corresponde à maneira como as pessoas encaram a proposta de mudança: você tem uma companhia quebrada e precisa consertá-la. Você contrata um mecânico. Ele troca as peças velhas que estiverem quebradas por outras, novas. A primeira explicação plausível para que a maioria dos esforços de mudança não dê muito certo é que as companhias não são máquinas. Na realidade são organismos vivos. Insistese em recorrer a mecânicos, quando, na realidade, precisa-se é de jardineiros (SENGE, 1999).

Insiste-se em tentar impor mudanças, quando o que se precisa é cultivar mudanças. Essa mentalidade mecânica pode complicar a vida de quem busca mudanças humanas por meio de aprendizagem organizacional ou com reorganizações e fusões.

As mudanças profundas acontecem apenas por meio do crescimento pessoal, aprendendo e desaprendendo.

Para SENGE (1999), a administração típica da era industrial, a organização e o modo de vida, nada disso vai continuar. A era industrial não é sustentável, nem em termos ecológicos nem humanos. A única dúvida é como isso vai mudar.

\subsection{Cooperativismo}

O termo cooperativa, para CRUZIO (1999), é: "a união de pessoas cujas necessidades individuais para o trabalho, para a comercialização ou para a prestação de serviços em grupo e respectivos interesses sociais, políticos e econômicos se fundem nos objetivos coletivos da associação". Ele aponta a forma de decidir sobre a organização como sendo a principal diferença entre 
cooperativa e as demais empresas. Na cooperativa, cada sócio representa um voto, todos com o mesmo peso, o mesmo poder, independentemente dos investimentos individuais. É o processo decisório que transforma os recursos dos acionistas (empresa) ou dos associados (cooperativa) em ativos, tais como os prédios e máquinas (CRUZIO, 1999)

Nesse modelo cooperativo, a autogestão utiliza-se dos mecanismos organizacionais e administrativos, próprios à participação do associado no processo de tomada de decisões e nos controles das respectivas ações. Essa participação do associado é que vai determinar o quê, como, quanto produzir, e onde aplicar os resultados desta produção.

Os anos 90 se apresentaram, conforme o pensamento de Michel THIOLLENT (1999), com muitos fatos novos, em relação à década dos 80 . Enquanto nesta década, o enfoque era mais assistencialista, com distribuição de recursos para as universidades e cooperação com as empresas, por meio do lema "as universidades devem ir ao mercado"; nos anos 90, houve uma maior interação com as empresas, novas demandas (mais sociais), surgimento de cooperativas populares, perspectivas de interesses mais sociais, não somente mercadológicas, crescimento das organizações não-governamentais (ONGs) e de outras experiências cooperativas, forçando com isto uma redefinição do papel das universidades, nesse contexto. O pesquisador aborda o papel da extensão universitária, como sendo cada vez mais relevante neste contexto; por ser um campo fértil de experimentações è vir a deflagrar uma nova demanda de produção de conhecimento. Considera, portanto, que é possível trabalhar com a extensão universitária, por meio de uma metodologia participativa em seus projetos, de tipo pesquisa-ação; principalmente, nas áreas de Educação; Comunicação e Metodologia da Pesquisa Científica e Social e Tecnologia Rural. Lembra que a metodologia participativa não pode ser considerada como um modismo, porque já existia em outros momentos históricos, a saber: no século XIX, nos anos 10 do século XX, com a Revolução Bolchevique (1917), nos anos 40, também, do século XX e anos 60, quando passou a ter uma metodologia mais consistente.

Certamente, o que se espera dos novos atores sociais, de hoje em dia, seja mais competição, porém, com muito mais cooperação!

\section{O PAPEL ESTRATÉGICO DA GERÊNCIA DE SISTEMAS DE INFORMAÇÃO}

A disciplina Administração de Sistemas de Informação, do Programa de Pós-Graduação em
Biblioteconomia e Ciência da Informação da PUC-Campinas, desenvolveu-se em três direções ou módulos: gestão estratégica do conhecimento, o papel estratégico de sistemas de informação e a gerência de sistemas de informação. Nesse sentido, foi ensinado que não podemos conceber a Administração Participativa como uma filosofia para o gerenciamento estratégico de sistemas de informação sem abordar os conceitos que as fundamentam: informação, sistema, redes e conhecimento.

Etimologicamente, informação vem do latim formatio (forma), e significa dar forma, criar e também representar, apresentar, criar uma idéia ou noção. O vocábulo é aplicado em vários campos do conhecimento, ganhando diferentes acepções. No contexto da Ciência da Informação, a informação é o seu próprio objeto de estudos e está profundamente relacionada aos Sistemas de Recuperação da Informação (SRI). Para DAVENPORT e PRUSAK (1998), diferentemente do dado, a informação tem significado. A "relevância e propósito" da definição de Drucker, ela não só "dá forma" ao receptor como ela própria tem uma forma: ela está organizada para alguma finalidade. Dados tornam-se informação quando o seu criador lhes acrescenta significado. Transformamos dados em informação agregando valor de diversas maneiras.

Sistema tem sua origem etimológica grega systema e significa combinar, trazer junto (syn-histanai). Trata-se de um conceito elaborado desde a Antigüidade, por filósofos gregos, na tentativa de entender o cosmos. Mas, é a partir da Teoria Geral de Sistemas (TGS) formulada por Bertalanffy, que a idéia de sistema se expande por muitas áreas e vai ser incorporada também na Ciência da Informação (PINHEIRO, 1997). No sentido estrito do termo, ou seja, aquele ligado à Ciência da Informação, estamos de acordo com FREIRE e ARAÚJO (1999) que consideram sistemas de informação como sinônimo de SRI. Nesta perspectiva, lidam com um tipo de informação: a que está potencialmente contida em documentos.

Redes, por sua vez, tem raíz indo-européia e significa "ligação por nós" e representa melhor o trabalho cooperativo e compartilhado, sendo mais flexível e menos rígida que sistema.

Quanto ao vocábulo conhecimento, este termo vem do latim conhecere e significa ter noção, idéia ou informação; ter consciência da própria existência, da própria capacidade. É objeto de estudo incessante dos epistemólogos. Interessa-nos, aqui, o termo do ponto de vista das organizações. Citando DAVENPORT e PRUSAK, novamente, temos: 


\begin{abstract}
"Conhecimento é umamisturafluida de experiência condensada, valores, informação contextual e insight experimentado, a qual proporciona uma estrutura para a avalização e incorporação de novas experiências e informações. Ele tem origem e é aplicado na mente dos conhecedores. Nas organizações, ele costuma estar embutido não só em documentos ou repositórios, mas também em rotinas, processos, práticas e normas organizacionais".
\end{abstract}

O que essa definição torna claro é que o conhecimento existe dentro das pessoas, faz parte das complexidade e imprevisibilidade humanas. Mais do que os dados e as informações, o conhecimento é o que está mais próximo da ação (práxis). Daí, o anseio de muitas empresas em conhecer quais são os seus conhecimentos tácitos, acumulados por um indivíduo, organização ou um conjunto delas; ao contrário dos conhecimentos codificados e de maior disponibilidade no mercado (LEMOS, 1999).

A partir dessa terminologia básica podemos refletir quão importante é a filosofia da Biblioteconomia e da Ciência da Informação nas sociedades informatizadas, a promoverem: a integração de pessoas e máquinas; ao redimensionarem serviços, com base nas novas tecnologias de informação, comunicação; ao desenvolverem novas habilidades no trato com as pessoas, principalmente, na resolução de conflitos; ao fornecerem novos conhecimentos aos já existentes, para serem melhor aproveitados e aplicados às demandas da sociedade e dos mercados e produzir resultados. Enfim, promover transformações sociais, com mais justiça e democracia, começando por colocar a informação como um bem de domínio público às classes excluídas da sociedade. O desafio está posto: de um lado, os indivíduos e, de outro, as redes. Seria o fím da História, como preconizava Fukuyama? O fim da razão, o fim dos modelos? Certamente, que não! O conhecimento continuará a se produzir em mentes criativas e empreendedoras que trabalham em prol da sociedade do conhecimento e da inteligência competitiva das empresas. Cada vez mais, o mapeamento de recursos de informação (fontes, serviços e sistemas) subsidiará a gerência de sistemas de informação, ao inovar os Sistemas de Informação para a Tomada de Decisão (Decision Support Systems), os Sistemas de Informação para a Qualidade Total; os Sistemas de Informação em Inteligência Competitiva e outros.

\section{CONCLUSÕES}

Pode-se concluir que o objetivo da Administração Participativa é alcançar a sinergia com os trabalhadores, onde o todo é maior que a soma das partes. Acabou a era autoritária nas organizações. Agora, gerenciar é sinônimo de liderar mobilizando esforços, atribuindo responsabilidades, delegando competências, motivando, debatendo, ouvindo sugestões, compartilhando os objetivos e, especialmente, transformando grupos em equipes/times.

Nas últimas décadas, porém, algumas tendências paralelas têm fortalecido a adoção do modelo de Administração Participativa. Isto deve-se a inúmeros fatores, como por exemplo: democratização das relações sociais, complexidade das empresas modernas, velocidade das mudanças, dentre outras.

Estes fatores de pertinência e importância, já conhecidos pela administração do extinto bloco socialista, estão também na raíz de alguns dos principais métodos japoneses de administração, que vinculam participação e organização, e têm demonstrado êxito, sendo amplamente reconhecidos e, até mesmo, copiados. Trata-se de conferir aos trabalhadores uma parcela de responsabilidade e um sentimento de parceria no sucesso obtido pela empresa. Entretanto, e novamente por tratar-se de relações humanas, o surgimento eventual de um conflito é imediatamente seguido por uma tentativa de resolução em todos os níveis que se fizerem necessários, nunca deixando para ocorrer a ocultação do problema, na espera que ele se resolva por si.

A Administração Participativa tem sido um dos aspectos mais abordados em administração de empresas. Reconhecidamente, há uma tendência mundial em humanizar cada vez mais seu funcionamento, e tratandose de relações humanas o conflito é inevitável, seja por choque de interesses ou mesmo de status. Conceder participação ao trabalhador na gestão de sua organização ou de seu setor dentro da organização, é muito mais do que uma técnica administrativa. Trata-se de uma filosofia ou mudança de mentalidade das pessoas em suas relações de trabalho.

Trata de um conceito emprestado da Administração Participativa e aplicado na Gerência de Sistemas de Informação como uma filosofia, ou seja, como um reflexo de uma mentalidade das pessoas em suas relações de trabalho.

\section{REFERÊNCIAS BIBLIOGRÁFICAS}

ARANHA, Maria Lúcia de Arruda; MARTINS, Maria Helena Pires. O pensamento político grego: a política nomativa. In: Filosofando: introdução à filosofia. 2. ed. São Paulo: Moderna,1995. p. 190-198.

AZEVEDO, Guiomar Goulart de. Geografia - v. 1: o espaço e os homens e o espaço brasileiro. São Paulo: Moderna, 1996. p. 148-149. 
CARVALHO, Irene C. de Almeida. Administração participativa como estratégia para a manutenção e o comprometimento com as mudanças organizacionais. Latin American Document Imaging Conference Seron: São Paulo, 1995.

COHEN, David. Mais esta agora: será que eu tenho de saber física quântica? Exame, São Paulo, v. 32, n. 23, p. 106-112, nov. 1998.

CRUZIO, Helnon de Oliveira. Organização e administração de cooperativas. Revista de Administração Pública, Rio de Janeiro, v. 33, n. 2, p. 39-58, mar./abr. 1999.

DAVENPORT, T.; PRUSAK, L. O que queremos dizer com conhecimento? In: Conhecimento empresarial. Rio de Janeiro: Campus, 1998. p. 1-28.

DÍAZ BORDENAVE, Juan E. O que é participação. 5. ed. São Paulo : Brasiliense, 1987.

FREIRE, Isa Maria; ARAÚJO, Vânia Maria Rodrigues Hermes de. A responsabilidade social da ciência da informação. Transinformação, Campinas, v. 11, n. 1, p. 7-15, jan./abr. 1999.

FERREIRA. A et al. Administração participativa. In: Gestão empresarial de Taylor aos nossos dias. São Paulo : Ed. Pioneira, 1998. p. 128-145.

LEMOS, Cristina. Inovação na era do conhecimento. In: LASTRES, Helena M. M.; ALBAGLI, Sarita (org.). Informação e globalização na era do conhecimento. Rio de Janeiro : Campus,1999. 318 p.; p.122-144.

MENDONÇA, Luis Eduardo Carvalheira de. Administração participativa: onde estão as resistências? Revista de Administração Pública, Rio de Janeiro, v. 26, n. 3, p.152-162, jul./set. 1992.
PASSOS, Carlos Artur Krüger. Novos modelos de gestão e as informações. In: LASTRES, Helena M. M.; ALBAGLI, Sarita (org.). Informação e globalização na era do conhecimento. Rio de Janeiro: Campus, 1999. p. 58-83.

PINHEIRO, Lena Vania R. Redes e sistemas de informações. Curso Aplicação da Tecnologia ao Desenvolvimento de Bibliotecas, programa de treinamento promovido pela Divisão de Gestão da Informação/Rede BIBLIODATA com o apoio da The Andrew W. Mellon Foundation. (1997), 30 p.

SEMLER, Ricardo. Virando a própria mesa. São Paulo : BestSeller, 1988

SENGE, Peter. Cuide do seu jardim. Exame, São Paulo, v. 32 , n. 12 , p. $82-87$, jun. 1999. Entrevista concedida a Alan Webber.

SILVA, Carlos Eduardo Luis da. Rifkin anuncia "fim do emprego". Folha de São Paulo 03/03/96. Mais! 5ำ caderno.

TAVARES, Hermes M. Produção flexível e planejamento territorial. Revista de Administração Pública, v. 26, n. 3, p. 163-73, jul./set. 1992 .

THIOLLENT, Michel. A metodologia participativa e sua aplicação em projetos de extensão universitária. Trabalho apresentado no III SEMPE - Seminário de Metodologia de Projetos de Extensão, UFSCar, São Carlos, SP, 26-27 de agosto de 1999. (Comunicação feita na UFPr, em Curitiba, em 07/10/99).

VEIGA, Aida. Tempos modernos. Veja, v. 33, n. 14, p. 122-129, 05/04/2000.

ZOHAR, Danah. O ser quântico. São Paulo: Best Seller, 1998 . 